\title{
From embedded nanoislands to thin films: Topographic and optical properties of europium oxide on $\mathrm{MgO}(001)$ films
}

\author{
Fernando Stavale, Leandro Pascua, Niklas Nilius, * and Hans-Joachim Freund \\ Fritz-Haber-Institut der Max-Planck-Gesellschaft, Faradayweg 4-6, D-14195 Berlin, Germany
}

(Received 19 April 2012; revised manuscript received 19 July 2012; published 24 August 2012)

\begin{abstract}
Combining scanning tunneling microscopy and cathodoluminescence spectroscopy, we have explored different routes to produce luminescent $\mathrm{MgO}_{\mathrm{Eu}}$ films on a $\mathrm{Mo}(001)$ support. Codeposition of Eu and $\mathrm{Mg}$ in an $\mathrm{O}_{2}$ ambience turned out to be unsuitable to prepare crystalline mixed oxides with distinct emission properties because of the large mismatch between the $\mathrm{Eu}$ and the $\mathrm{Mg}$ ion radius. In contrast, highly luminescent samples were obtained after annealing $\mathrm{MgO}$-supported Eu particles in oxygen. The optically active species were identified as nanosized $\mathrm{Eu}_{2} \mathrm{O}_{3}$ islands embedded in the first $\mathrm{MgO}$ layer, while single $\mathrm{Eu}$ ions inside the host lattice are of minor importance. The $\mathrm{MgO}_{\mathrm{Eu}}$ adsorption system exhibits a rich photon spectrum that comprises five emission bands in the wavelength region between 565 and $725 \mathrm{~nm}$. They are assigned to electron transitions from the ${ }^{5} \mathrm{D}_{0}$ excited to the ${ }^{7} \mathrm{~F}_{J}$ ground states of $\mathrm{Eu}^{3+}$, with the $J$ quantum number running from 0 to 4 . From the relative intensities of certain $J$ transitions, we conclude that the respective $\mathrm{Eu}^{3+}$ ions occupy sites without inversion symmetry, a condition that is best fulfilled by Eu species at the perimeter of the $\mathrm{Eu}_{2} \mathrm{O}_{3}$ nanoislands. With increasing exposure, a europium-oxide film develops on top of the $\mathrm{MgO}$ surface, whose weak spectral signature is compatible with $\mathrm{Eu}^{3+}$ ions in more centrosymmetric surroundings. Our work demonstrates that relevant properties of Eu-based phosphors, being typically prepared in the form of powder samples, can be generated in thin-film systems as well, the latter being accessible to a range of surface-science techniques due to their finite conductivity.
\end{abstract}

DOI: 10.1103/PhysRevB.86.085448

PACS number(s): 68.55.Ln, 78.66.Sq, 68.37.Ef, 78.60.Hk

\section{INTRODUCTION}

Rare earth (RE) metal oxides and simple oxides doped with $\mathrm{RE}$ ions have fascinating electronic, optical, and chemical properties and are found in various applications, ranging from fuel cells, gas sensors, and biosensors to inorganic light emitters and heterogeneous catalysts. ${ }^{1,2}$ The specific properties of the RE compounds are governed by the distinct nature of their $4 f$ states that are positioned close to the Fermi level but still feature the spatial localization of a core level. ${ }^{3}$ The $4 f$ orbitals are subject to negligible overlap with neighboring states, giving rise to atomiclike electronic and optical excitations in those materials. ${ }^{4}$ Moreover, the occupancy of the $4 f$ orbitals can be easily altered, which makes the corresponding oxides good electron donors or acceptors. ${ }^{5}$

A traditional yet powerful approach to investigate RE species in wide-gap insulators is optical spectroscopy. ${ }^{1,6}$ The RE ions imprint distinct absorption and emission lines onto the optical response of the host material, which contain detailed information on their local environment and charge state. The optical signature results from electron transitions inside the $4 f$-state manifold that are often dipole forbidden due to the constant angular-momentum quantum number across the transition. However, the dipole selection rules are softened if the RE ion sits in a noncentrosymmetric crystal field or experiences temporal position changes due to vibrations of the host lattice, ${ }^{7,8}$ resulting in the appearance of narrow zero-phonon and phonon-assisted optical transitions in the RE spectra. ${ }^{9}$

The interplay between binding symmetry and optical response was analyzed in detail for trivalent $\mathrm{Eu}^{3+}$ impurities embedded in various inorganic hosts. ${ }^{10-14}$ The Eu ions typically adopt a ${ }^{7} \mathrm{~F}_{0}$ ground-state configuration, while the primary light-emitting state is a ${ }^{5} \mathrm{D}_{0}$ configuration. ${ }^{1}$ Optical transitions occur mainly from the ${ }^{5} \mathrm{D}_{0}$ to the ${ }^{7} \mathrm{~F}_{J}(0<J<6)$ manifold, giving rise to a series of red emission lines with intensities depending on the local $\mathrm{Eu}^{3+}$ environment. From all possible transitions, only ${ }^{5} \mathrm{D}_{0} \rightarrow{ }^{7} \mathrm{~F}_{1}$ is magnetically dipole allowed in the free ion; all others require $J$-level mixing induced by the crystal field. ${ }^{12,15}$ Whereas the odd-parity components of the crystal field enable electric dipole transitions between ${ }^{5} \mathrm{D}_{0}$ and ${ }^{7} \mathrm{~F}_{2,4,6}$ in the first order, a combination of odd and even crystal-field terms gives rise to faint second-order transitions for the remaining $J=0,3,5$ values. The intensities of the different $J$ transitions, and in particular of the hypersensitive $J=2$ peak, thus provide a good measure of the local crystal field acting on the $\mathrm{Eu}^{3+}$ ions.

The common route to investigate the optical behavior of Eu-doped inorganic phosphors is the preparation of powder samples with large active volume and hence high emission yield. ${ }^{11-17}$ The main drawback of this approach is the limited access to local structural and electronic properties of the Eu ions, because powerful microscopic and spectroscopic techniques are often unable to explore the morphologically complex and electrically insulating powder oxides. Conclusions on the $\mathrm{Eu}^{3+}$ lattice sites are therefore drawn from comparing the optical results with predictions obtained from a grouptheoretical treatment of the possible binding geometries. ${ }^{1,8}$ In this work, we try to overcome these restrictions by fabricating idealized model systems for Eu phosphors that can be accessed with the established methodology of surface science. ${ }^{18,19}$ For this purpose, $\mathrm{MgO}$ thin films were grown on a Mo(001) single crystal and functionalized by either inserting $\mathrm{EuO}_{x}$ aggregates or adsorbing them onto the surface. Our approach enables comprehensive insight into structural and morphological properties of the $\mathrm{MgO}_{\mathrm{Eu}}$ system by means of low-energy electron diffraction (LEED) and scanning 


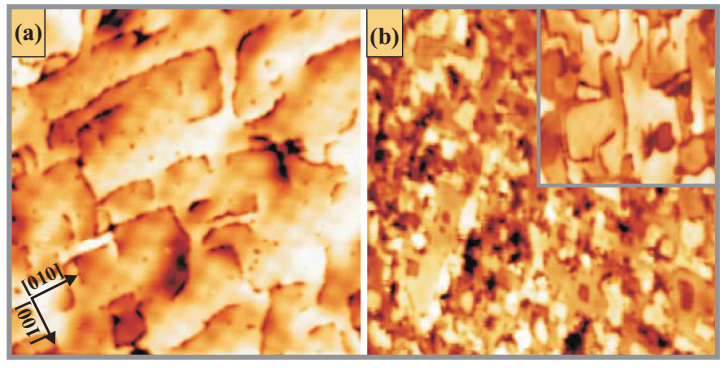

FIG. 1. (Color online) (a) STM topographic image of a pristine 10-ML-thick $\mathrm{MgO}$ film $\left(5.0 \mathrm{~V}, 140 \times 140 \mathrm{~nm}^{2}\right)$. (b) $\mathrm{MgO}_{\text {Eu }}$ mixed film produced by codepositing nominally $10 \mathrm{ML}$ of $\mathrm{Mg}$ and $0.5 \mathrm{ML}$ of Eu in $\mathrm{O}_{2}\left(140 \times 140 \mathrm{~nm}^{2}\right)$. The main image in (b) was obtained after heating the sample to $800 \mathrm{~K}$, while the inset shows the film after annealing to $1100 \mathrm{~K}$.

tunneling microscopy (STM). Optical characterization was carried out with a variation of cathodoluminescence spectroscopy, in which the electron beam generated by the STM tip is used for a spatially localized excitation. ${ }^{20}$ This method was already employed to explore the emission properties of individual metal particles, ${ }^{21}$ quantum-well structures, ${ }^{22,23}$ and molecules, ${ }^{24}$ but it has hardly been applied to oxide nanostructures due to their limited conductivity. However, a number of promising experiments were recently reported in this respect, e.g., on the role of defects and lattice impurities on the optical characteristics of bare $\mathrm{MgO}^{25}$ and $\mathrm{ZnO},{ }^{26}$ as well as of $\mathrm{Cr}$-doped $\mathrm{MgO}^{27}$ and Er-doped $\mathrm{SiO}_{2} \cdot{ }^{28} \mathrm{In}$ this work, we combine the imaging and spectroscopic abilities of STM to analyze the interplay between geometric and optical properties of $\mathrm{MgO}_{\mathrm{Eu}}$ at the local scale.

\section{EXPERIMENTAL DETAILS}

The experiments were performed in a specifically designed, liquid-nitrogen-cooled STM that enabled photon detection out of a large solid angle of the tip-sample junction. ${ }^{29}$ The setup consisted of a beetle-type STM head being placed in the center of a parabolic mirror. A second mirror focused the light onto the entrance slit of a grating spectrograph, equipped with gratings that had 150 and 600 lines $/ \mathrm{mm}$, combined with a charge-coupled-device detector. The instrument allowed us to detect ultralow photon fluxes in a wavelength range of 200-1200 nm. The spectral resolutions were 4 and $1 \mathrm{~nm}$ for the 150 - and 600-line/ $\mathrm{mm}$ grating, respectively. The vacuum chamber $\left(2 \times 10^{-10}\right.$ mbar base pressure $)$ was further equipped with standard preparation and analysis tools, e.g., a quartz microbalance and a four-grid LEED/Auger system.

The $\mathrm{MgO}$ host was prepared by physical vapor deposition of $\mathrm{Mg}$ in $5 \times 10^{-7}$ mbar $\mathrm{O}_{2}$ onto a sputtered $(1500-\mathrm{eV}$ $\mathrm{Ar}^{+}$ions $)$and annealed $(2000 \mathrm{~K}) \mathrm{Mo}(001)$ crystal at $300 \mathrm{~K}^{30}$ Crystallization was achieved by tempering the film at $1000 \mathrm{~K}$ in vacuum. The film thickness was chosen between 10 and 50 monolayers (ML), depending on the scope of the experiment. LEED measurements revealed a square $(1 \times 1)$ pattern, indicative of a rocksalt $\mathrm{MgO}(001)$ surface. At low thicknesses, the diffraction spots displayed a cross shape, reflecting a certain oxide mosaicity. The film surface comprised atomically flat, rectangular terraces $10-20 \mathrm{~nm}$ in size, separated by predominately [100]-directed dislocation lines [Fig. 1(a)]. The latter developed due to lattice strain induced by Mo support and neighboring oxide grains. The line defects appeared as 1-nm-wide troughs in STM images taken at positive sample bias because they exhibited reduced electron transmissibility due to a locally enhanced work function. ${ }^{25}$ Closer inspection revealed a faint square pattern on top of the film surface, the remnant of an interfacial $\mathrm{MgO}-\mathrm{Mo}$ coincidence lattice. Small $\mathrm{Eu}$ quantities, calibrated with a quartz microbalance, were either embedded into or deposited onto the $\mathrm{MgO}$ films using an e-beam evaporator.

\section{RESULTS}

\section{A. Film preparation and topographic characterization}

Two approaches were pursued to prepare $\mathrm{MgO}_{\mathrm{Eu}}$ systems: codeposition of $\mathrm{Mg}$ and $\mathrm{Eu}$ in an $\mathrm{O}_{2}$ ambience (referred to as mixed systems) and deposition of Eu metal onto the $\mathrm{MgO}$ surface followed by an annealing step in $\mathrm{O}_{2}$ (referred to as ad-systems). In the first case, 5 at\% of Eu was added to the $\mathrm{Mg}-\mathrm{O}_{2}$ gas vapor used for oxide growth, and the sample was annealed to $800 \mathrm{~K}$ in vacuum thereafter. As a result, we obtained a nanocrystalline film that still exhibited the $(1 \times 1)$ LEED pattern of rocksalt $\mathrm{MgO}$ but showed a rough surface morphology with terrace sizes below $5 \mathrm{~nm}$ [Fig. 1(b)]. Apparently, the Eu strongly perturbed the crystallization process, and well-ordered $\mathrm{MgO}$ films were only obtained after annealing to $1000 \mathrm{~K}$ [Fig. 1(b), inset]. However, the better structural quality in that case did not indicate better accommodation of the Eu ions but rather their removal from the oxide lattice due to segregation and evaporation. ${ }^{31}$

Typical $\mathrm{MgO}_{\mathrm{Eu}}$ ad-systems are shown in Fig. 2 for comparison. After deposition of $0.5 \mathrm{ML}$ of metallic $\mathrm{Eu}$, particles 1-3 $\mathrm{nm}$ in diameter and $1 \mathrm{~nm}$ in height were found on the surface. Most of them nucleated along the $\mathrm{MgO}$ dislocation lines, where linear aggregates developed at higher exposure [Fig. 2(a)]. ${ }^{32}$ To stimulate Eu diffusion into the film, we annealed the samples to different temperatures in $5 \times 10^{-7} \mathrm{mbar}$ $\mathrm{O}_{2}$. Vacuum annealing only led to Eu desorption, because the bare metal reached substantial vapor pressures already at low temperatures $\left(10^{-6}\right.$ mbar at $600 \mathrm{~K}$ compared to $1800 \mathrm{~K}$ for $\left.\mathrm{Eu}_{2} \mathrm{O}_{3}\right) .{ }^{33}$ Still, most $\mathrm{Eu}$ evaporated during a typical $800-\mathrm{K}$ annealing step in oxygen, and only a small fraction penetrated the surface in the form of small nanoinclusions with a distinct STM appearance [Fig. 2(b)-2(d)]. The latter displayed a couple of maxima surrounded by a dark ring and rose no more than $0.1 \mathrm{~nm}$ above the $\mathrm{MgO}$ surface [Fig. 2(c)]. Because metal deposits are typically imaged as plain protrusions in $\mathrm{STM},{ }^{32}$ we suggest the $\mathrm{Eu}$ to be fully oxidized in those structures and even incorporated into the first $\mathrm{MgO}$ plane. The diameter of the islands was found to depend on the Eu load and increased from 2 to $10 \mathrm{~nm}$ (diameter of the dark ring) when increasing the exposure from 0.1 to 1 ML. Similar to the original metal deposits, most islands were found along the $\mathrm{MgO}$ dislocation lines, with only a few examples located on the oxide terraces. Apparently, the $\mathrm{EuO}_{x}$ islands were preferentially stabilized at $\mathrm{MgO}$ surface defects at high annealing temperatures. With increasing $\mathrm{Eu}$ exposure, the surface turned rough as increasing amounts of 


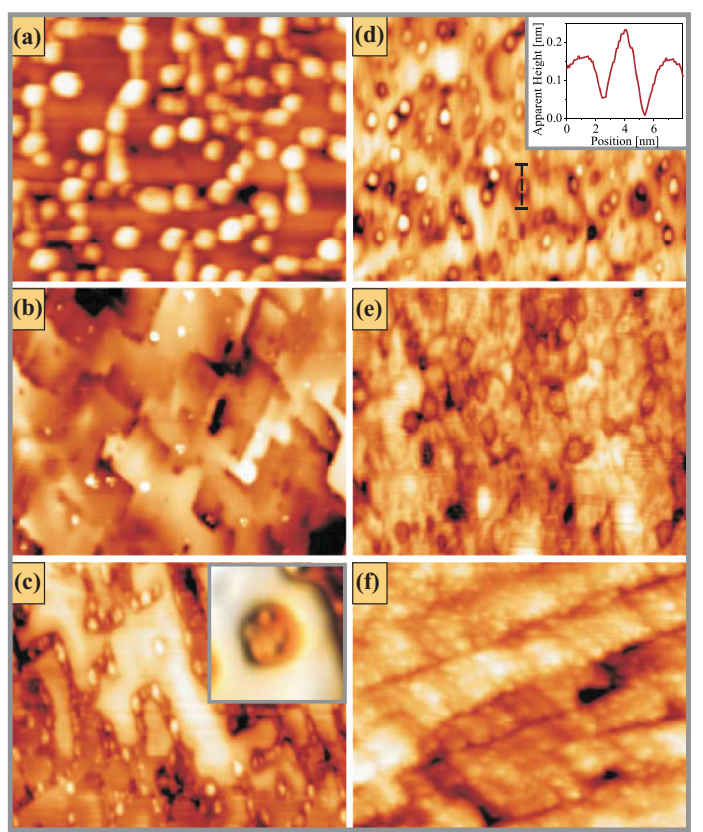

FIG. 2. (Color online) (a) STM topographic image of 0.5 ML of metallic Eu deposited onto $10 \mathrm{ML}$ of $\mathrm{MgO}$ at $300 \mathrm{~K}$. Images of (b) 0.05 , (c) 0.2 , (d) 0.5 , and (e) $1 \mathrm{ML}$ of Eu dosed on $10 \mathrm{ML}$ of $\mathrm{MgO}$ and annealed to $800 \mathrm{~K}$ in $5 \times 10^{-7} \mathrm{mbar} \mathrm{O}_{2}$. The inset in (c) displays a single $\mathrm{EuO}_{x}$ island in a pseudo-three-dimensional fashion $\left(8 \times 8 \mathrm{~nm}^{2}\right)$. The inset in $(\mathrm{d})$ is a height profile across the $\mathrm{EuO}_{x}$ island marked in the main panel. (f) $\mathrm{MgO}$ film after depositing $10 \mathrm{ML}$ of $\mathrm{Eu}$ and annealing in $5 \times 10^{-7}$ mbar $_{2}$ at $800 \mathrm{~K}$.

material survived the high-temperature $\mathrm{O}_{2}$ treatment. Finally, a granular film without a long-range order developed on the $\mathrm{MgO}$ surface [Fig. 2(e) and 2(f)]. Given its large heat of oxidation of $608 \mathrm{~kJ} / \mathrm{mol},{ }^{33}$ the $\mathrm{Eu}$ is likely to be fully oxidized in these films, an assumption confirmed with Auger spectroscopy. Unfortunately, no distinction between $\mathrm{Eu}^{2+}$ and $\mathrm{Eu}^{3+}$, as in $\mathrm{EuO}$ and $\mathrm{E}_{2} \mathrm{O}_{3}$, respectively, was possible with our Auger system; however, we show later in this paper that most $\mathrm{Eu}$ is in the $3+$ charge state.

\section{B. Optical characterization of the $\mathrm{MgO}_{\mathrm{Eu}}$ films}

Optical characterization of the $\mathrm{MgO}_{\mathrm{Eu}}$ systems was accomplished by cathodoluminescence spectroscopy performed in our STM setup. For this purpose, the tip was biased with $-200 \mathrm{~V}$, and a field-emission current of $5 \mathrm{nA}$ was stabilized with the feedback loop. The photon emission was accumulated for $300 \mathrm{~s}$ and analyzed for different monochromator slit widths and optical gratings. The surface region used for spectroscopy was imaged before and after each spectral run to verify the integrity of the oxide film and to exclude electron-induced damage. Figure 3 (top spectrum) shows the emission response of a pristine $10-\mathrm{ML}$-thick $\mathrm{MgO}$ film. It was governed by a photon peak at $400 \mathrm{~nm}$, originating from the radiative decay of $\mathrm{MgO}$ excitons trapped at threefold coordinated oxygen sites, as discussed in earlier work. ${ }^{30,34,35}$ Most recombination centers were located along the $\mathrm{MgO}$ dislocation lines ${ }^{36}$ and became blocked upon $\mathrm{Eu}$ deposition, causing the 400-nm peak to disappear. After annealing in $\mathrm{O}_{2}$, the $\mathrm{MgO}$ emission partly

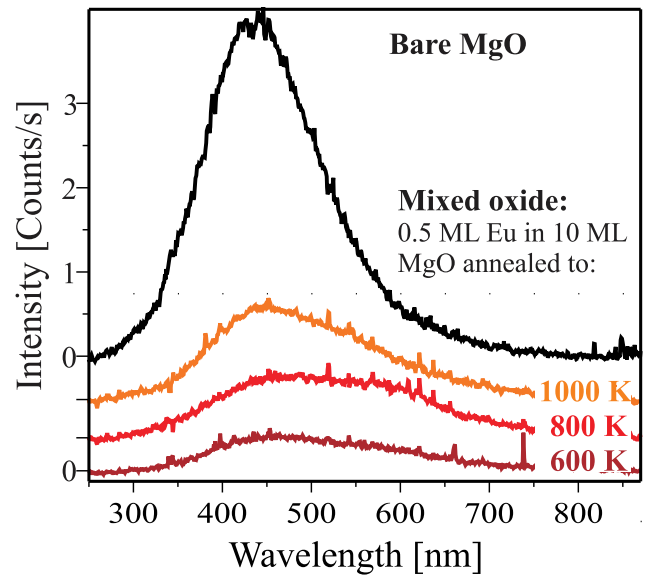

FIG. 3. (Color online) Cathodoluminescence spectra of bare $\mathrm{MgO}$ (black) and mixed $\mathrm{MgO}_{\mathrm{Eu}}$ taken at $200-\mathrm{eV}$ electron energy, 5-nA current, and 300-s accumulation time. The spectra are offset for clarity.

recovered because some excitonic traps were cleared due to sintering and evaporation of the adsorbed metal. In addition, a new emission peak appeared $\sim 615 \mathrm{~nm}$, matching the signature of the most intense $\mathrm{Eu}^{3+}$ optical bands [Fig. 4]. ${ }^{1,10}$ Evidently, the $\mathrm{O}_{2}$ treatment transformed optically inactive Eu metal into a luminescent oxide compound. Because the occurrence of the 615-nm peak coincided with the formation of $\mathrm{EuO}_{x}$ islands on the $\mathrm{MgO}$ surface, we suggest the latter to be responsible for the emission response.

Evidence for this correlation came from spectral series taken as a function of Eu load [Fig. 4]. With increasing exposure yet identical post-treatment conditions, the $615-\mathrm{nm}$ line gained intensity while the 400-nm peak disappeared, a process that suggests continued formation of $\mathrm{Eu}^{3+}$ centers at the expense of $\mathrm{MgO}$ excitonic traps. The respective STM images showed an increasing number of $\mathrm{EuO}_{x}$ islands on the surface [Fig. 2]. Simultaneously, the emission course developed a distinct fine structure, characterized by maxima at

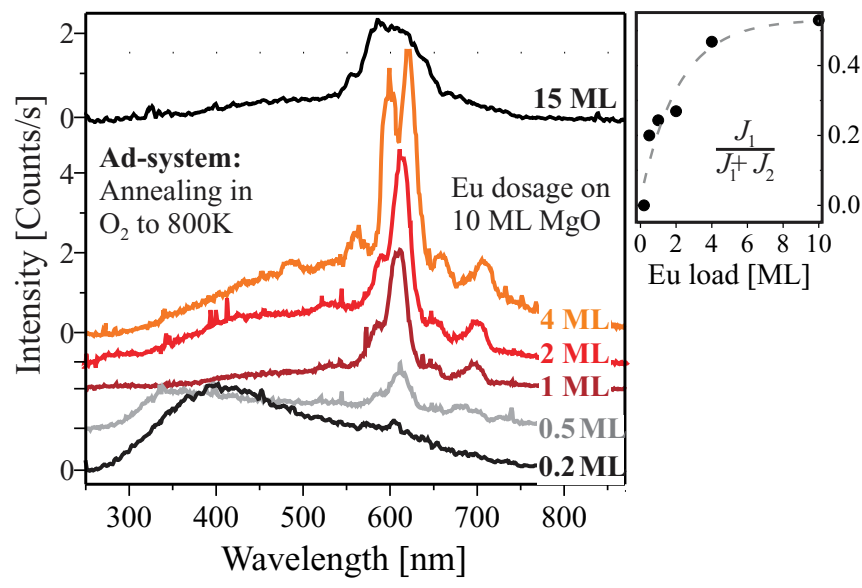

FIG. 4. (Color online) Cathodoluminescence spectra of $10 \mathrm{ML}$ of $\mathrm{MgO}$ and increasing amounts of Eu. All samples were annealed in $\mathrm{O}_{2}$ at $800 \mathrm{~K}$ before spectral acquisition. The inset shows the intensity ratio between $J=1$ and $J=2$ emission bands at 600 and $615 \mathrm{~nm}$, respectively, as a function of the initial Eu load. 


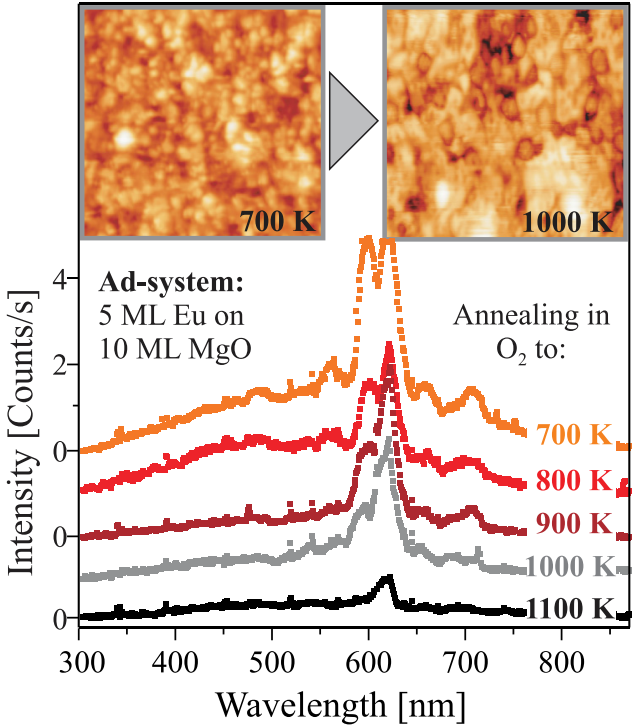

FIG. 5. (Color online) Cathodoluminescence spectra of $5 \mathrm{ML}$ of $\mathrm{Eu}$ on $10 \mathrm{ML}$ of $\mathrm{MgO}$ after annealing in $\mathrm{O}_{2}$ to the given temperatures. Curves are offset for clarity. The surface morphology at the beginning and end of the annealing series is displayed in the insets $\left(60 \times 60 \mathrm{~nm}^{2}\right)$.

585,650 , and $700 \mathrm{~nm}$ besides the $615-\mathrm{nm}$ main band. Above an $\sim 5$-ML nominal Eu load, a new band was detected at $\sim 600 \mathrm{~nm}$, a spectral change that corresponded with the formation of a $\mathrm{EuO}_{x}$ film on the $\mathrm{MgO}$ surface [Fig. 2(f)]. Evidently, the spectral signature of the closed film differed from the one of the nanoislands. At even higher exposure, the $600-\mathrm{nm}$ band developed into the dominant spectral feature but slowly faded beyond 10-ML-EuO $x$ thickness.

The reverse trend was revealed when starting with a 5-ML-thick $\mathrm{EuO}_{x}$ film and exposing it to $\mathrm{O}_{2}$ at increasingly high temperatures [Fig. 5]. Two STM images taken before and after the series reflect the associated morphological changes. At $700 \mathrm{~K}$, the entire surface was covered with a disordered $\mathrm{EuO}_{x}$ film that, in accordance to the previous paragraph, gave rise to an emission peak at $600 \mathrm{~nm}$. The presence of a second band at $615 \mathrm{~nm}$ indicated that the development of $\mathrm{EuO}_{x}$ nanoislands in the $\mathrm{MgO}$ top plane had already started at this point. Raising the temperature to 800,900 , and $1000 \mathrm{~K}$ caused the intensity of the 600 -nm band to decrease by almost $70 \%$, while the $615-\mathrm{nm}$ emission lost only $1 / 4$ of its original value. This spectral evolution suggests gradual evaporation of the ad-oxide, a process that hardly affected the $\mathrm{EuO}_{x}$ inclusions in the $\mathrm{MgO}$ surface that remained unchanged until $1000 \mathrm{~K}$. This scenario was supported by STM images taken after the $1000-\mathrm{K}$ annealing step that displayed the bare $\mathrm{MgO}$ surface covered by a few $\mathrm{EuO}_{x}$ islands. Annealing to an even higher temperature recovered the pristine $\mathrm{MgO}$ morphology and emission characteristics.

Given the small emission yield of ultrathin oxide films, the optical spectra presented so far were acquired with low spectral resolution. To gain better insight into position, width, and intensity of the photon lines, we prepared a highly luminescent film by depositing $10 \mathrm{ML}$ of Eu onto $50 \mathrm{ML}$ of $\mathrm{MgO}$, followed by an annealing step at $1000 \mathrm{~K}$ in $5 \times 10^{-7} \mathrm{mbar}_{2}$. The resulting sample showed a sharp $\mathrm{MgO}(1 \times 1)$ LEED pattern

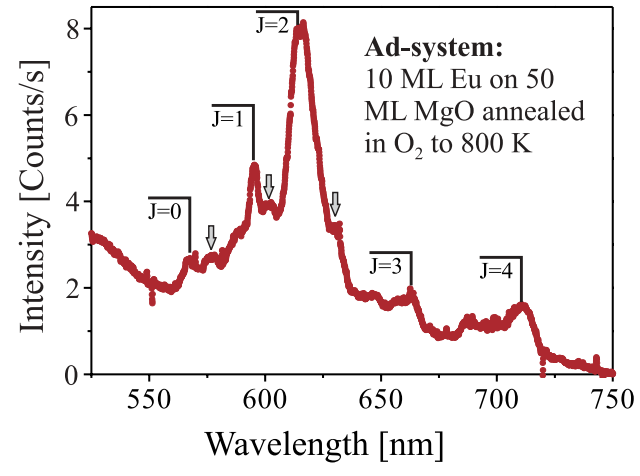

FIG. 6. (Color online) High-resolution cathodoluminescence spectrum (600-line/mm grating) of a film prepared by depositing $10 \mathrm{ML}$ of $\mathrm{Eu}$ onto $50 \mathrm{ML}$ of $\mathrm{MgO}$ and annealing to $1000 \mathrm{~K}$ in $\mathrm{O}_{2}$. The $J$ quantum numbers for different ${ }^{5} \mathrm{D}_{0} \rightarrow{ }^{7} \mathrm{~F}_{J}$ transitions are indicated.

but was too thick for STM imaging. We expect, however, a similar surface morphology as in Fig. 2(e) due to identical preparation conditions. The large free mean path of the $200-\mathrm{eV}$ electrons rendered cathodoluminescence spectroscopy feasible in this case-yielding 10-fold-higher photon intensity, as for 10-ML films. We explain this enhancement with better decoupling of the optical centers from the Mo support, which is known to quench any luminescence. The high intensity allowed us to work with a grating of 600 lines $/ \mathrm{mm}$ and a narrow monochromator slit width to improve resolution [Fig. 6]. The respective spectrum contained more than 12 emission lines between 565 and $750 \mathrm{~nm}$, with the narrowest one having a full-width-at-half-maximum (FWHM) of $1.0 \mathrm{~nm}$ only. An overview of the resolved photon peaks is given in Table I. The quality and richness of this spectrum is compatible with photoluminescence data obtained on bulk and powder samples, although the number of optically active centers in our films was orders of magnitudes smaller. This illustrates

TABLE I. Summary of wavelengths of the main emission bands detected on our thick $\mathrm{MgO}_{\mathrm{Eu}}$ films [Fig. 6], in comparison with earlier photoluminescence data for Eu-doped $\mathrm{MgO}$ powders.

\begin{tabular}{|c|c|c|c|c|}
\hline $\begin{array}{l}\text { Peak } \\
\text { number }\end{array}$ & $\begin{array}{l}\text { Wavelength } \\
\quad(\mathrm{nm})\end{array}$ & $\begin{array}{c}\text { Peak positions } \\
\text { in Eu-MgO } \\
\text { powder samples }{ }^{\mathrm{a}} \\
(\mathrm{nm})\end{array}$ & $\begin{array}{l}\text { Peak positions } \\
\text { in Eu-MgO } \\
\text { nanocrystals }^{\text {b }} \\
(\mathrm{nm})\end{array}$ & $\begin{array}{l}\text { Final state } \\
\text { of optical } \\
\text { transition }\end{array}$ \\
\hline 1 & 569 & & 580 & ${ }^{7} \mathrm{~F}_{0}$ \\
\hline 2 & 577 & 581 & 584 & ${ }^{7} \mathrm{~F}_{0}$ \\
\hline 3 & 588 & 588 & & ${ }^{7} F_{1}$ \\
\hline 4 & 595 & 596 & 594 & ${ }^{7} \mathrm{~F}_{1}$ \\
\hline 5 & 602 & 600 & & ${ }^{7} F_{1}$ \\
\hline 6 & 615 & 612 & 615 & ${ }^{7} F_{2}$ \\
\hline 7 & 617 & 615 & 616 & ${ }^{7} \mathrm{~F}_{2}$ \\
\hline 8 & 630 & 630 & & ${ }^{7} \mathrm{~F}_{2}$ \\
\hline 9 & 647 & & & ${ }^{7} \mathrm{~F}_{3}$ \\
\hline 10 & 663 & 655 & 654 & ${ }^{7} \mathrm{~F}_{3}$ \\
\hline 11 & 688 & & 706 & ${ }^{7} \mathrm{~F}_{4}$ \\
\hline 12 & 710 & & 725 & ${ }^{7} \mathrm{~F}_{4}$ \\
\hline
\end{tabular}

${ }^{\mathrm{a}}$ From Ref. 16.

${ }^{\mathrm{b}}$ From Ref. 17. 
the large potential of the thin-film approach, especially because structural and morphological data are also available.

Conversely, mixed films prepared by $\mathrm{Eu} / \mathrm{Mg}$ codeposition had rather featureless spectra that we do not discuss in detail [Fig. 3, lower spectra]. Upon annealing to $600 \mathrm{~K}$, only a broad shoulder at $600 \mathrm{~nm}$ appeared next to the 400-nm exciton band. At higher temperatures, this shoulder became sharper but never displayed any fine structure. It vanished after annealing to $1100 \mathrm{~K}$ due to Eu desorption. We believe that incomplete crystallization of the $\mathrm{MgO}$ in the presence of the Eu impurities is responsible for the faint emission response, following the explanation given in the literature. ${ }^{1,16}$

\section{DISCUSSION}

The starting point for analyzing the emission properties of Eu-containing phosphors is the elucidation of the local crystal field and its impact on the free-ion emission, which requires knowledge on the $\mathrm{Eu}$ binding sites in the host lattice. $1,10,37,38$ The structure of $\mathrm{MgO}_{\mathrm{Eu}}$ mixed systems is governed by the size mismatch between $\mathrm{Eu}^{3+}(110 \mathrm{pm})$ and $\mathrm{Mg}^{2+}$ ions $(65 \mathrm{pm}) .{ }^{33}$ Substitution of $\mathrm{Mg}$ with Eu therefore leads to a lattice distortion that obstructs the development of an ordered mixed phase. Low miscibility was concluded from substantial line broadening in the spectra of $\mathrm{MgO}_{\mathrm{Eu}}$ powder samples due to the presence of several nonequivalent $\mathrm{Eu}$ binding geometries in the rocksalt lattice. ${ }^{16,17}$ Our data support this interpretation, because $\mathrm{MgO}_{\mathrm{Eu}}$ mixed films always feature a high surface roughness and a low emission cross section [Figs. 1(b) and 3]. We assume that Eu does not atomically disperse in the $\mathrm{MgO}$ lattice but rather forms small aggregates to minimize distortion of adjacent crystalline regions. The charge imbalance due to individual Eu ions in the $3+$ charge state might be compensated for by inserting $\mathrm{Mg}$ vacancies into the $\mathrm{MgO}$ lattice, a mechanism that was demonstrated for the example of $\mathrm{Cr}^{3+}$ dispersed in $\mathrm{MgO}^{6,27}$ In general, $\mathrm{Cr}$ incorporation into the rocksalt lattice is promoted by the matching ion radius of $\mathrm{Cr}^{3+}(75 \mathrm{pm})$ with respect to the one of the substituted $\mathrm{Mg}^{2+}$. As a result, $\mathrm{MgO}_{\mathrm{Cr}}$ mixed films with good crystallinity and distinct emission properties can be prepared, although no well-ordered films develop upon $\mathrm{Eu}$ and $\mathrm{Mg}$ codeposition in oxygen.

However, highly luminescent $\mathrm{MgO}_{\mathrm{Eu}}$ samples were obtained by oxidizing small quantities of metallic Eu on the $\mathrm{MgO}$ surface. The respective STM images display a large density of presumably monolayer islands, made of oxidized Eu [Fig. 2(c) and 2(d)]. The number of $\mathrm{Eu}$ ions in each nanoinclusion is below 100, as estimated from the mean island diameter $(3 \mathrm{~nm})$ and the $\mathrm{Eu}-\mathrm{Eu}$ distance in bulk $\mathrm{Eu}_{2} \mathrm{O}_{3}(0.36 \mathrm{~nm})$. While half of the ions are located along the perimeter to $\mathrm{MgO}$ and have at least three $\mathrm{O}_{\mathrm{MgO}}$ neighbors, the other half sit in the island interior and have only one $\mathrm{O}_{\mathrm{MgO}}$ beneath them. We believe that the perimeter species are mainly responsible for the emission response and find evidence for this in the well-resolved optical spectra taken on thick $\mathrm{MgO}_{\mathrm{Eu}}$ films [Fig. 6]. Five bands are identified between 565 and $750 \mathrm{~nm}$ that can be assigned to transitions from the ${ }^{5} \mathrm{D}_{0}$ excited to ${ }^{7} \mathrm{~F}_{J}$ final states of $\mathrm{Eu}^{3+}$, with the total angular-momentum quantum number $J$ running from 0 to 4 . $^{1}$ Their centers of gravity are $\sim 573 \mathrm{~nm}(J=0), 595 \mathrm{~nm}(J=1), 620 \mathrm{~nm}(J=2), 665 \mathrm{~nm}$
$(J=3)$, and $700 \mathrm{~nm}(J=4)$, in good agreement with the results from $\mathrm{MgO}_{\mathrm{Eu}}$ powder samples discussed in Refs. 16 and 17 (Table I). This correspondence is no verification for the presence of identical sites in the various samples, because crystal-field effects lead only to minor perturbations of the ${ }^{5} \mathrm{D}_{0} \rightarrow{ }^{7} \mathrm{~F}_{J}$ transition energies and similar peaks are found in rather different host oxides. ${ }^{10-13}$

Clearly, the peak related to the $J=2$ final state has the highest intensity. The corresponding transition becomes forced-dipole allowed only due to odd-parity components of the crystal field acting on $\mathrm{Eu}^{3+}$. These odd-parity terms soften the constraints set by the dipole selection rules as they stimulate mixing of the different $4 f$ states and of the $4 f$ and $5 d \mathrm{Eu}$ orbitals. ${ }^{13,39}$ The high intensity of the $J=$ 2 peak thus suggests that the respective $\mathrm{Eu}^{3+}$ ions occupy sites without inversion symmetry and are subject to a crystal field that is governed by odd-parity terms. ${ }^{13}$ This condition is best fulfilled for $\mathrm{Eu}$ ions at the perimeter of the nanoislands, which interact simultaneously with the $\mathrm{O}$ ligands from $\mathrm{MgO}$ and $\mathrm{EuO}_{x}$ and hence experience an asymmetric crystal field. The relatively strong $J=4$ peak $\sim 710 \mathrm{~nm}$ supports the presence of $\mathrm{Eu}^{3+}$ species in noncentrosymmetric sites, because its intensity is determined by odd-parity crystal-field terms as well. The $J_{0}$ and $J_{3}$ transitions, however, are hardly detected because they become optically active only in the second order due to a mixing of odd and even components of the local crystal field. ${ }^{15}$ Moreover, all $J$ transitions display at least one high-wavelength satellite, as marked by arrows in Fig. 6. For $J=1-4$, this might be explained by the intrinsic $J$ degeneracy of the respective transitions, whereas the splitting of the nondegenerate $J=0$ level requires the presence of two different $\mathrm{Eu}^{3+}$ sites in our samples. We tentatively assign the two species to $\mathrm{Eu}^{3+}$ ions located at the perimeter and in the interior of the surface islands. Alternatively, the second peak might arise from Eu species dissolved in the $\mathrm{MgO}$ lattice. The dipole-forbidden transitions might also be enabled by vibronic effects that lead to a temporary lowering of the $\mathrm{Eu}^{3+}$ binding symmetry. ${ }^{9}$ As shown for Cr-doped $\mathrm{MgO}$, phonon-mediated optical bands may even dominate the cathodoluminescence spectra due to an effective phonon excitation in this case. ${ }^{27}$ However, optical transitions in RE ions are known to be less sensitive to vibronic effects, given the strong shielding of their $4 f$ states by the outer $5 \mathrm{~s} p$ shell. ${ }^{1}$ Moreover, the satellites do not appear at the expected wavelength position of $17 \mathrm{~nm}$ above the zero-phonon line that would be in line with the maximum in the $\mathrm{MgO}$ phonon density of states. ${ }^{9}$

Particularly interesting is an analysis of the $J=1$ peak at $\sim 600 \mathrm{~nm}$ that has not been addressed so far. ${ }^{37,39}$ The ${ }^{5} \mathrm{D}_{0} \rightarrow{ }^{7} \mathrm{~F}_{1}$ transition is magnetically dipole allowed even in the free ion and generates an emission peak for $\mathrm{Eu}^{3+}$ in centrosymmetric sites. Its strength can thus be used to estimate the total amount of $\mathrm{Eu}$ in a given sample, independent of the local binding geometry. ${ }^{15}$ For samples with a low initial Eu load, the $J=1$ peak is roughly four times weaker than the $J=2$ peak, suggesting that most $\mathrm{Eu}^{3+}$ occupies odd-symmetry sites [Fig. 4, inset]. This ratio changes with increasing coverage, and the $J=1$ peak rises much faster than $J=2$ once a closed $\mathrm{EuO}_{x}$ film develops on the $\mathrm{MgO}$ surface. We explain the dominance of the ${ }^{5} \mathrm{D}_{0} \rightarrow{ }^{7} \mathrm{~F}_{1}$ transition in this case by the absence of

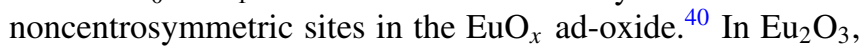


being the thermodynamically preferred oxide phase, the $\mathrm{Eu}^{3+}$ ions occupy sites of distorted octahedral symmetry for which transitions into the ${ }^{7} \mathrm{~F}_{2}$ final state are dipole forbidden and only the ${ }^{7} \mathrm{~F}_{1}$ state gives rise to a weak emission response. The evolution of the $J=1 / J=2$ ratio therefore reflects the amount of $\mathrm{Eu}^{3+}$ localized either in the closed $\mathrm{EuO}_{x}$ film or in the nanoislands. Consequently, the $J=1$ intensity is found to increase with Eu exposure as the closed $\mathrm{EuO}_{x}$ layer gains thickness [Fig. 4]. Conversely, the peak diminishes with annealing temperature, because the ad-oxide evaporates much faster than the inclusions embedded in the $\mathrm{MgO}$ surface plane [Fig. 5].

Finally, the FWHM of the $J=1$ peak was found to be as large as $25 \mathrm{~nm}$ for thick $\mathrm{EuO}_{x}$ films [Fig. 4, top curve], which compares to $1 \mathrm{~nm}$ for the surface islands. We assign this broadening to a lifetime effect, because the dense $\mathrm{Eu}^{3+}$ packing in the ad-oxide promotes Förster-type dilution of the original oscillator strength and enables energy transfer to nonradiative decay centers. ${ }^{41}$ Clearly, these processes are less relevant for the nanoislands that contain only a small number of optically active centers. In addition, inhomogeneous broadening due to the presence of different $\mathrm{Eu}^{3+}$ species in the poorly ordered thick films might contribute to the large width of the $J=1$ peak.

\section{CONCLUSIONS}

Using STM topographic imaging and cathodoluminescence spectroscopy, we have shown that optically active samples can be prepared by annealing $\mathrm{MgO}$-supported Eu clusters in $\mathrm{O}_{2}$. In this procedure, $\mathrm{EuO}_{x}$ islands develop on the $\mathrm{MgO}$ surface, featuring intense light emission at $\sim 600 \mathrm{~nm}$. The emission is governed by optical transitions within the $4 f$-state manifold of $\mathrm{Eu}^{3+}$ ions and becomes dipole allowed due to the impact of a noncentrosymmetric crystal field. We believe that single Eu ions in the $\mathrm{MgO}$ matrix play only a minor role for the observed photon response, because the large $\mathrm{Eu}^{3+}$ ion radius impedes incorporation into the $\mathrm{MgO}$ lattice.

The results discussed here could only be obtained on a thinfilm model system that has several advantages with respect to powder samples commonly used for luminescence studies. Thin films can be accessed by surface-science techniques, and important aspects of RE phosphors may thus be addressed with different microscopic and spectroscopic techniques. Our STM-based approach even enables a local detection of the optical response, although the capacity of the method could not be exhausted here because of the large electron energy required for excitation. Still, the possibility to correlate morphological and optical properties of surfaces on a nanometer scale may open interesting routes to elucidate the physics and chemistry of RE materials.

\section{ACKNOWLEDGMENTS}

F.S. thanks the Alexander von Humboldt Foundation for financial support. We are grateful to K. P. Vogelgesang for his help in constructing the experimental setup and to W. D. Schneider for insightful discussions. The authors acknowledge support from the Deutsche Forschungsgemeinschaft through the Cluster of Excellence UniCat. *nilius@fhi-berlin.mpg.de

${ }^{1}$ S. Huefner, Optical Spectra of Transparent Rare Earth Compounds (Academy Press, New York, 1978).

${ }^{2}$ A. Trovarelli, Catalysis by Ceria and Related Materials (Imperial College Press, London, 2002).

${ }^{3}$ N. V. Skorodumova, S. I. Simak, B. I. Lundqvist, I. A. Abrikosov, and B. Johansson, Phys. Rev. Lett. 89, 166601 (2002).

${ }^{4}$ E. Wuilloud, B. Delley, W. D. Schneider, and Y. Baer, Phys. Rev. Lett. 53, 202 (1984).

${ }^{5}$ G. N. Vayssilov, Y. Lykhach, A. Migani, T. Staudt, G. P. Petrova, N. Tsud, T. Skála, A. Bruix, F. Illas, K. C. Prince, V. Matolin, K. M. Neyman, and J. Libuda, Nat. Mater. 10, 310 (2010).

${ }^{6} \mathrm{~B}$. Henderson and G. Imbusch, Optical Spectroscopy of Inorganic Solids (Clarendon Press, Oxford, UK, 1989).

${ }^{7}$ G. F. Imbusch, A. L. Schawlow, A. D. May, and S. Sugano, Phys. Rev. 140, A830 (1965).

${ }^{8}$ Y. Tanabe and S. Sugano, J. Phys. Soc. Jpn. 9, 753 (1954); 9, 766 (1954).

${ }^{9}$ M. J. L. Sangster, Phys. Rev. B 6, 258 (1972).

${ }^{10}$ G. Blasse, A. Bril, and W. C. Nieuwpoo, J. Phys. Chem. Solid. 27, 1587 (1966)

${ }^{11}$ G. Blasse, Prog. Solid State Chem. 18, 79 (1988).

${ }^{12}$ A. Abdelkader and M. M. Elkholy, J. Mater. Sci. 27, 2887 (1992).

${ }^{13}$ A. F. Kirby, D. Foster, and F. S. Richardson, Chem. Phys. Lett. 95, 507 (1983).
${ }^{14}$ A. Kumar, S. Babu, A. S. Karakoti, A. Schulte, and S. Seal, Langmuir 25, 10998 (2009).

${ }^{15}$ T. Qin, G. Mountjoy, N. D. Afify, M. F. Reid, Y. Y. Yeung, A. Speghini, and M. Bettinelli, Phys. Rev. B 84, 104206 (2011).

${ }^{16} \mathrm{~J}$. Alarcon, D. van der Voort, and G. Blasse, Mat. Res. Bull. 27, 467 (1992).

${ }^{17}$ L. Peng, Y. Wang, Z. Wang, and Q. Dong, Appl. Phys. A 102, 387 (2011).

${ }^{18}$ D. F. Förster, J. Klinkhammer, C. Busse, S. G. Altendorf, T. Michely, Z. Hu, Y. Y. Chin, L. H. Tjeng, J. Coraux, and D. Bourgault, Phys. Rev. B 83, 045424 (2011).

${ }^{19}$ N. Nilius, Surf. Sci. Rep. 64, 595 (2009).

${ }^{20} \mathrm{R}$. Berndt, in Scanning Probe Microscopy, Springer Series Nanoscience and Technology, edited by R. Wiesendanger (Springer, Berlin, 1998), pp. 97.

${ }^{21}$ N. Nilius, N. Ernst, and H.-J. Freund, Phys. Rev. Lett. 84, 3994 (2000).

${ }^{22}$ G. Hoffmann, J. Kliewer, and R. Berndt, Phys. Rev. Lett. 87, 176803 (2001).

${ }^{23}$ U. Hakanson, M. K. Johansson, M. Holm, C. Pryor, L. Samuelson, and W. Seifert, Appl. Phys. Lett. 81, 4443 (2002).

${ }^{24}$ X. H. Qui, G. V. Nazin, and W. Ho, Science 299, 542 (2003).

${ }^{25}$ H. M. Benia, P. Myrach, and N. Nilius, New J. Phys. 10, 013010 (2008); H. M. Benia, P. Myrach, A. Gonchar, T. Risse, N. Nilius, and H.-J. Freund, Phys. Rev. B 81, 241415(R) (2010). 
${ }^{26}$ E. Likovich, R. Jaramillo, J. Russell Kasey, S. Ramanathan, and V. Narayanamurti, Appl. Phys. Lett. 99, 151910 (2011).

${ }^{27}$ F. Stavale, N. Nilius, and H.-J. Freund, New J. Phys. 14, 033006 (2012).

${ }^{28}$ J. Fiala, H. Omi, and T. Tawara, J. Nanophotonics 6, 063503 (2012).

${ }^{29}$ H.-J. Freund, N. Nilius, T. Risse, S. Schauermann, and T. Schmidt, Chem. Phys. Chem. 12, 79 (2011).

${ }^{30}$ S. Benedetti, H. M. Benia, N. Nilius, S. Valeri, and H.-J. Freund, Chem. Phys. Lett. 430, 330 (2006); S. Benedetti, P. Torelli, S. Valeri, H. M. Benia, N. Nilius, and G. Renaud, Phys. Rev. B 78, 195411 (2008).

${ }^{31}$ T. Suzuki, S. Hishita, K. Oyoshi, and R. Souda, Surf. Sci. 391, L1243 (1997).

${ }^{32}$ S. Benedetti, P. Myrach, A. di Bona, S. Valeri, N. Nilius, and H.-J. Freund, Phys. Rev. B 83, 125423 (2011).

${ }^{33}$ D. R. Lide (Ed.), CRC Handbook of Chemistry and Physics (CRC Press, Boca Raton, FL, 2010).
${ }^{34}$ M. Anpo, Y. Yamada, Y. Kubokawa, S. Coluccia, A. Zecchina, and M. Che, J. Chem. Soc. Faraday Trans. 84, 751 (1988).

${ }^{35}$ S. Stankic, M. Muller, O. Diwald, M. Sterrer, E. Knözinger, and J. Bernardi, Angew. Chem. Int. Ed. 44, 4917 (2005); S. Stankic, J. Bernardi, O. Diwald, and E. Knözinger, J. Phys. Chem. B 110, 13866 (2006).

${ }^{36}$ H. M. Benia, X. Lin, H. J. Gao, N. Nilius, and H.-J. Freund, J. Phys. Chem. C 111, 10528 (2007).

${ }^{37}$ Q. P. Wang, Y. P. Gao, and A. Bulou, J. Phys. Chem. Solid. 56, 285 (1995).

${ }^{38}$ A. Huignard, V. Buissette, A. C. Franville, T. Gacoin, and J. P. Boilot, J. Phys. Chem. B 107, 6754 (2003).

${ }^{39}$ T. Kushida and M. Tanaka, Phys. Rev. B 65, 195118 (2002).

${ }^{40}$ W. Chen, A. G. Joly, C. M. Kowalchuk, J. O. Malm, Y. N. Huang, and J. O. Bovin, J. Phys. Chem. B 106, 7034 (2002).

${ }^{41}$ A. P. Demchenko, Introduction to Fluorescence Sensing (Springer, Berlin, 2008), pp. 91. 